Sādhanā Vol. 40, Part 7, October 2015, pp. 2073-2093. (C) Indian Academy of Sciences

\title{
Numerical investigation into entropy generation in a transient generalized Couette flow of nanofluids with convective cooling
}

\author{
M H MKWIZU $^{1,3, *}$, O D MAKINDE ${ }^{2}$ and \\ YAW NKANSAH-GYEKYE ${ }^{1}$ \\ ${ }^{1}$ School of Computational and Communication Science and Engineering, \\ Nelson Mandela African Institution of Science and Technology, (NM-AIST), \\ P.O. Box 447, Arusha, Tanzania \\ ${ }^{2}$ Faculty of Military Science, Stellenbosch University, Private Bag X2, \\ Saldanha 7395, South Africa \\ ${ }^{3}$ Department of Biometry and Mathematics, Sokoine University of Agriculture, \\ P O BOX 3038, Morogoro, Tanzania \\ e-mail: mkwizum@nm-aist.ac.tz; makinded@gmail.com; \\ yaw.nkansah-gyekye@nm-aist.ac.tz
}

MS received 28 July 2014; revised 27 January 2015; accepted 9 July 2015

\begin{abstract}
This work investigates the effects of convective cooling on entropy generation in a transient generalized Couette flow of water-based nanofluids containing Copper $(\mathrm{Cu})$ and Alumina $\left(\mathrm{Al}_{2} \mathrm{O}_{3}\right)$ as nanoparticles. Both First and Second Laws of thermodynamics are utilised to analyse the problem. The model partial differential equations for momentum and energy balance are tackled numerically using a semidiscretization finite difference method together with Runge-Kutta Fehlberg integration scheme. Graphical results on the effects of parameter variation on velocity, temperature, skin friction, Nusselt number, entropy generation rate, irreversibility ratio and Bejan number are presented and discussed.
\end{abstract}

Keywords. Channel flows; nanofluids; Couette flow; entropy generation; Bejan number.

\section{Introduction}

Theoretical study of nanofluids heat transfer characteristics and entropy generation between two parallel plates, one of which is moving relative to the other under the combined action of axial pressure gradient and imposed uniform velocity on the upper plate known as generalised Couette flow not only present a mathematical fascinating problems but also find various applications in engineering and industrial processes such as tribological devices, cooling of heat exchanging

*For correspondence 
devices, solar water heating, cooling of electronics, cooling of transformer oil, improving diesel generator efficiency, improving heat transfer efficiency of chillers, domestic refrigeratorfreezers, cooling in machining and in nuclear reactor. Nanofluid is the addition of nanoscale particles into the base fluid like water, engine oil, and ethylene glycol. It was first used by Choi (1995) who was working with Argonne National Laboratory in the USA. The research done by Choi showed that nanofluids possess enhanced thermophysical properties. Nanofluid may be considered as a single phase flow in low solid concentration because of very small sized solid particles. Several experimental and theoretical studies have been made on the flow of nanofluids in different geometries (Choi et al 2001; Abu-Nada 2008; Makinde \& Aziz 2011; Makinde 2012, 2013a; Mutuku-Njane \& Makinde 2013; Olanrewaju \& Makinde 2013; Motsumi \& Makinde 2012). The nanofluid in the enclosure was assumed to be in single phase. It was found that, for any given Grash of number, the average Nusselt number increased with the solid volume concentration parameter. Modelling of nanofluids flow over a convectively heated unsteady stretching sheet was considered by Makinde (2013a, b). Oztop \& Abu-Nada (2008) considered natural convection in partially heated enclosures having different aspect ratios and filled with nanofluid. They found that the heat transfer was more pronounced at low aspect ratio and high volume fraction of nanoparticles. Wang \& Mujumdar (2007) presented a comprehensive review of heat transfer characteristics of nanofluids. Detailed reports on convective transport in nanofluids can be found in Buongiorno (2006), Mutuku-Njane \& Makinde (2014), and Tiwari \& Das (2007).

Meanwhile, the primary objective in designing a thermal system is the analysis of energy utilization and entropy generation. It has been the main concern in many fields such as heat exchangers, turbo machinery, electronic cooling, porous media and combustion. Knowledge of entropy production started from Clausius and Kelvin's studies on the irreversible aspects of the second law of thermodynamics. Since then the theories based on these foundations have rapidly developed, Bejan $(1982,1996)$. Optimal designs of thermodynamic systems have been extensively suggested by the thermodynamic second law (Woods 1975) based on the concept of efficient energy use and the minimal entropy generation principle. Entropy generation minimization techniques may improve the efficiency and overall performance of all kinds of flow and thermal systems. Makinde \& Eegunjobi (2013) did the study on thermodynamic analysis of variable viscosity magnetohydrodynamics (MHD) unsteady generalized Couette flow with permeable walls. It was found that local entropy generation rate increases with group parameter but decreases with viscosity exponent. Increase in magnetic field parameter decreases entropy production at the moving upper plate while increase in Reynolds number decreases entropy generation at the lower fixed plate. Thermodynamic analysis of variable viscosity MHD unsteady generalized Couette flow with permeable walls by Makinde \& Theuri (2014). The obtained result was that the decrease in fluid viscosity increases the Bejan number while an increase group parameter $\mathrm{Br} \Omega^{-1}$ (where $\Omega$ is temperature difference parameter and $\mathrm{Br}$ Brinkman number) decreases the Bejan number. Increase in Reynolds number increases Bejan number at the lower fixed plate and decreases Bejan number at the upper moving plate. The situation reversed with increasing magnetic field. Several studies have thoroughly dealt with conventional fluid flow irreversibility due to viscous effect and heat transfer by conduction (Narusawa 1998; Sahin 1998; Makinde \& Aziz 2010; Makinde \& Beg 2010). Numerous investigations to calculate entropy production and irreversibility due to flow and heat transfer of nanofluids over a moving flat surface were considered by Makinde et al (2013). Their observation was that the entropy generation in the flow system is minimized by appropriate combination of parameter values together with nanoparticles volume fraction. Moreover, the entropy generation analysis with respect to nanofluids flow under various physical situations has remained untreated by 
classical thermodynamics. This motivates many researchers to conduct analyses of fundamental and applied engineering problems based on second law analysis with respect to nanofluid flow.

In this paper, we focus on the analysis of the effects of convective cooling and entropy generation rate in unsteady generalized Couette flow of water base nanofluids. We have made use of a single component homogenous model in describing the nanofluids (Abu-Nada 2008; Makinde \& Aziz 2011; Makinde 2012, 2013a, b; Mutuku-Njane \& Makinde 2013; Olanrewaju \& Makinde 2013; Motsumi \& Makinde 2012; Oztop \& Abu-Nada 2008; Wang \& Mujumdar 2007). The justification of this model is based on the fact that the particles size are of nano-meter (1-100 $\mathrm{nm}$ ) and these particles are mechanically and chemically suspended into the base fluid, consequently, the entire flow behaviour is similar to homogenous fluid with different thermophysical properties due to the presence of nano-sized particles (Choi 1995; Choi et al 2001). In addition, the single component homogenous model enables one to compare the flow/thermal behaviour of $\mathrm{Cu}$-water nanofluid to that of $\mathrm{Al}_{2} \mathrm{O}_{3}$-water nanofluid. We are fully aware of the Buongiorno (2006) models approach which incorporates the effects of thermophoresis and Brownian motion of nanoparticles. This model approach has been utilised in some of our earlier studies. Secondly, we have assumed no-slip condition at both the fixed lower plate and the moving upper plate; however, the movement of the fluid near the upper plate is due to the impose uniform velocity of the upper plate and the axial pressure gradient (Makinde \& Eegunjobi 2013; Makinde \& Theuri 2014). The mathematical model for the problem is formulated in the next section. Entropy analysis is done in section 3 . In section 4, the model equations formulated in section 2 are numerically solved. Relevant results are displayed graphically and discussed in section 5 . The final section concludes the paper.

\section{Mathematical model}

Consider unsteady generalised Couette flow of viscous incompressible nanofluids containing Copper $(\mathrm{Cu})$ and Alumina $\left(\mathrm{Al}_{2} \mathrm{O}_{3}\right)$ as nanoparticles. It is assumed that the upper wall moves with uniform velocity $U$ at time $t>0$ and exchange heat with the ambient surrounding following the Newton's law of cooling. Take a Cartesian coordinate system $(x, y)$ where $x$ lies along the flow direction, $y$ is the distance measured in the normal direction as depicted in figure 1 .

The Navier-Stokes nanofluids momentum and energy balance equation in one dimension for the transient flow can be written as (Olanrewaju \& Makinde 2013; Motsumi \& Makinde 2012;

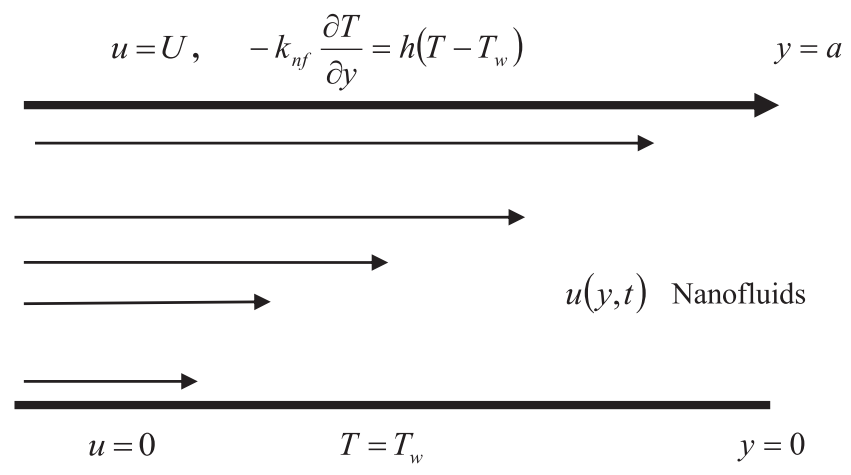

Figure 1. Schematic diagram of the problem under consideration. 
Makinde 2012, 2013b; Oztop \& Abu-Nada 2008; Wang \& Mujumdar 2007; Buongiorno 2006)

$$
\begin{gathered}
\frac{\partial u}{\partial x}=0 \\
\frac{\partial u}{\partial \bar{t}}=-\frac{1}{\rho_{n f}} \frac{\partial P}{\partial x}+\frac{\mu_{n f}}{\rho_{n f}} \frac{\partial^{2} u}{\partial y^{2}} \\
\frac{\partial T}{\partial \bar{t}}=\alpha_{n f} \frac{\partial^{2} T}{\partial y^{2}}+\frac{\alpha_{n f} \mu_{n f}}{k_{n f}}\left(\frac{\partial u}{\partial y}\right)^{2},
\end{gathered}
$$

where $u$ is the nanofluid velocity in the $x$-direction, $T$ is the temperature of the nanofluid, $P$ is the nanofluid pressure, $\bar{t}$ is the time, $a$ is the channel width, $T_{w}$ is the ambient temperature, $\mu_{n f}$ is the dynamic viscosity of the nanofluid, $k_{n f}$ is the nanofluid thermal conductivity, $\rho_{n f}$ is the density of the nanofluid and $\alpha_{n f}$ is the thermal diffusivity of the nanofluid which are given below as (Abu-Nada 2008; Makinde 2012, 2013a; Bejan 1982);

$$
\begin{aligned}
& \mu_{n f}=\frac{\mu_{f}}{(1-\phi)^{2.5}}, \rho_{n f}=(1-\varphi) \rho_{f}+\varphi \rho_{s}, \\
& \alpha_{n f}=\frac{k_{n f}}{\left(\rho c_{p}\right)_{n f}}, \tau=\frac{\left(\rho c_{p}\right)_{s}}{\left(\rho c_{p}\right)_{f}}, \frac{k_{n f}}{k_{f}}=\frac{\left(k_{s}+2 k_{f}\right)-2 \varphi\left(k_{f}-k_{s}\right)}{\left(k_{s}+2 k_{f}\right)+\varphi\left(k_{f}-k_{s}\right)}, \\
& \left(\rho c_{p}\right)_{n f}=(1-\varphi)\left(\rho c_{p}\right)_{f}+\varphi\left(\rho c_{p}\right)_{s}
\end{aligned}
$$

The nanoparticles volume fraction is represented by $\varphi\left(\varphi=0\right.$ correspond to a regular fluid), $\rho_{f}$ and $\rho_{s}$ are the densities of the base fluid and the nanoparticle respectively, $k_{f}$ and $k_{s}$ are the thermal conductivities of the base fluid and the nanoparticles respectively, $\left(\rho c_{p}\right)_{f}$ and $\left(\rho c_{p}\right)_{s}$ are the heat capacitance of the base fluid and the nanoparticle respectively. It is worth mentioning that the use of the above expression for $k_{n f}$, is restricted to spherical nanoparticles (Makinde 2012; Oztop \& Abu-Nada 2008; Tiwari \& Das 2007) and does not account for other shapes of nanoparticles. Also, the effective viscosity of the nanofluid $\mu_{n f}$ with respect to that of base fluid $\mu_{f}$ containing dilute suspension of fine spherical particles is approximated as described in Eq. (4) (Oztop \& Abu-Nada 2008; Tiwari \& Das 2007). The initial and boundary conditions are given as follows:

$$
\begin{gathered}
u(y, 0)=0, \quad T(y, 0)=T_{w}, \\
u(0, \bar{t})=0, T(0, \bar{t})=T_{w}, \\
u(a, \bar{t})=U,-k_{n f} \frac{\partial T}{\partial y}(a, \bar{t})=h\left(T(a, \bar{t})-T_{w}\right),
\end{gathered}
$$

where $T_{w}$ is the ambient temperature which also corresponds to the lower wall temperature. Table 1 below presents thermophysical properties of water, copper and alumina at the reference temperature.

Table 1. Thermophysical properties of the fluid phase (water) and nanoparticles (Makinde 2012; Makinde \& Eegunjobi 2013; Makinde \& Theuri 2014).

\begin{tabular}{lccc}
\hline Physical properties & Fluid phase (water) & $\mathrm{Cu}$ & $\mathrm{Al}_{2} \mathrm{O}_{3}$ \\
\hline$c_{p}(\mathrm{~J} / \mathrm{kg} \mathrm{K})$ & 4179 & 385 & 765 \\
$\rho\left(\mathrm{kg} / \mathrm{m}^{3}\right)$ & 997.1 & 8933 & 3970 \\
$\mathrm{k}(\mathrm{W} / \mathrm{m} \mathrm{K})$ & 0.613 & 401 & 40 \\
\hline
\end{tabular}


We introduce the dimensionless variables and parameters into Eqs. (1)-(7) as follows:

$$
\begin{aligned}
& \theta=\frac{T-T_{w}}{T_{w}}, \quad W=\frac{u}{U}, \quad t=\frac{\bar{t} U}{a}, \quad v_{f}=\frac{\mu_{f}}{\rho_{f}}, \bar{P}=\frac{P a}{\mu_{f} U}, \\
& A=-\frac{\partial \bar{P}}{\partial X}, \quad X=\frac{x}{a}, \eta=\frac{y}{a}, \operatorname{Pr}=\frac{\mu_{f} c_{p f}}{k_{f}}, E c=\frac{U^{2}}{c_{P f} T_{a}}, \quad \text {. } \\
& \left.\tau=\frac{\left(\rho c_{p}\right)_{s}}{\left(\rho c_{p}\right)_{f}}, m=\frac{\left(k_{s}+2 k_{f}\right)+\varphi\left(k_{f}-k_{s}\right)}{\left(k_{s}+2 k_{f}\right)-2 \varphi\left(k_{f}-k_{s}\right)}, R e=\frac{U a}{v_{f}} \quad\right\}
\end{aligned}
$$

The dimensionless governing equations together with the appropriate initial and boundary conditions can be written as

$$
\begin{gathered}
\frac{\partial W}{\partial t}=\frac{A}{\operatorname{Re}\left(1-\varphi+\varphi \rho_{s} / \rho_{f}\right)}+\frac{1}{\operatorname{Re}\left(1-\varphi+\varphi \rho_{s} / \rho_{f}\right)(1-\varphi)^{2.5}} \frac{\partial^{2} W}{\partial \eta^{2}}, \\
\frac{\partial \theta}{\partial t}=\frac{1}{m \operatorname{Pr} \operatorname{Re}(1-\varphi+\varphi \tau)} \frac{\partial^{2} \theta}{\partial \eta^{2}}+\frac{E c}{\operatorname{Re}(1-\varphi+\varphi \tau)(1-\varphi)^{2.5}}\left(\frac{\partial W}{\partial \eta}\right)^{2},
\end{gathered}
$$

with initial and boundary conditions

$$
\begin{gathered}
W(\eta, 0)=\theta(\eta, 0)=0, \\
W(0, t)=\theta(0, t)=0, \\
W(1, t)=1, \quad \frac{\partial \theta}{\partial \eta}(1, t)=-m B i \theta(1, t),
\end{gathered}
$$

where $B i$ is the Biot number, $\mathrm{Pr}$ is the Prandtl number, $E c$ is the Eckert number and $\mathrm{A}$ is the pressure gradient parameter. Other physical quantities of practical interest in this problem are the skin friction coefficient $C_{f}$ and the local Nusselt number $N u$ which are defined as

$$
C_{f}=\frac{a \tau_{w}}{\mu_{f} U}, N u=\frac{a q_{w}}{k_{f} T_{w}},
$$

where $\tau_{w}$ is the wall shear stress and $q_{w}$ is the heat flux at the channel walls given by

$$
\tau_{w}=\left.\mu_{n f} \frac{\partial u}{\partial y}\right|_{y=a}, q_{w}=-\left.k_{n f} \frac{\partial T}{\partial y}\right|_{y=a} .
$$

Substituting Eqs. (15) into (14) and using dimensionless variables, we obtain

$$
\left.\begin{array}{l}
C_{f}=\frac{1}{(1-\varphi)^{2.5}} \frac{\partial W}{\partial \eta} \\
N u=-\frac{1}{m} \frac{\partial \theta}{\partial \eta}
\end{array}\right\} \text { at } \eta=1 .
$$

\section{Entropy analysis}

The second law of thermodynamics is an important tool to scrutinize the irreversibility effects due to flow and heat transfer. Thermodynamic irreversibility is closely related to entropy production. Convection process involving channel flow of nanofluids is inherently irreversible due to 
the exchange of energy and momentum, within the nanofluid and at solid boundaries. Following Woods (1975), the local volumetric rate of entropy generation is given by

$$
S^{\prime \prime \prime}=\frac{k_{n f}}{T_{w}^{2}}\left(\frac{\partial T}{\partial y}\right)^{2}+\frac{\mu_{n f}}{T_{w}}\left(\frac{\partial u}{\partial y}\right)^{2} .
$$

The first term in Eq. (17) is the entropy generation due to heat transfer while the second term is the entropy generation due to fluid friction. Using dimensionless variables from Eq. (8), we express the entropy generation number in dimensionless form as,

$$
N s=\frac{a^{2} S^{\prime \prime \prime}}{k_{f}}=\frac{1}{m}\left(\frac{\partial \theta}{\partial \eta}\right)^{2}+\frac{B r}{(1-\varphi)^{2.5}}\left(\frac{\partial W}{\partial \eta}\right)^{2},
$$

where $B r=E c$ Pr is the Brinkmann number.

Let

$$
N_{1}=\frac{1}{m}\left(\frac{\partial \theta}{\partial \eta}\right)^{2}, N_{2}=\frac{B r}{(1-\varphi)^{2.5}}\left(\frac{\partial W}{\partial \eta}\right)^{2},
$$

The irreversibility distribution ratio is defined as $\Phi=N_{2} / N_{1}$. Heat transfer irreversibility dominates for $0 \leq \Phi<1$ and fluid friction irreversibility dominates when $\Phi>1$. The contribution of both irreversibilities to entropy generation is equal when $\Phi=1$. We define the Bejan numbers $(\mathrm{Be})$ mathematically as

$$
B e=\frac{N_{1}}{N s}=\frac{1}{1+\Phi} .
$$

Equation (20) shows that the Bejan number ranges from 0 to 1 . The zero value of the Bejan number corresponds to the limit where the irreversibility is dominated by the effect of fluid friction while $B e=1$ is the limit where the irreversibility due to heat transfer dominates the flow system. The contribution of both heat transfer and fluid friction to irreversibility are the same when $B e=0.5$.

\section{Numerical procedure}

Using a semi-discretization finite difference method (method of lines Woods 1975), the nonlinear initial boundary value problem (IBVP) in Eqs. (9)-(13) can be solved numerically. We partition the spatial interval $0 \leq \eta \leq 1$ into $N$ equal parts and define grid size $\Delta \eta=1 / N$ and grid points $\eta_{i}=(i-1) \Delta \eta, 1 \leq i \leq N+1$. The discretization is based on a linear Cartesian mesh and uniform grid on which finite-differences are taken. The first and second spatial derivatives in Eqs. (9)-(10) are approximated with second-order central finite differences. Let $W_{i}(t)$ and $\theta_{i}(t)$ be approximation of $W\left(\eta_{i}, t\right)$ and $\theta\left(\eta_{i}, t\right)$, then the semi-discrete system for the problem becomes

$$
\begin{gathered}
\frac{d W_{i}}{d t}=\frac{A}{\operatorname{Re}\left(1-\varphi+\varphi \rho_{s} / \rho_{f}\right)}+\frac{\left(W_{i+1}-2 W_{i}+W_{i-1}\right)}{\operatorname{Re}\left(1-\varphi+\varphi \rho_{s} / \rho_{f}\right)(1-\varphi)^{2.5}(\Delta \eta)^{2}}, \\
\frac{d \theta_{i}}{d t}=\frac{\left(\theta_{i+1}-2 \theta_{i}+\theta_{i-1}\right)}{m \operatorname{Pr} \operatorname{Re}(1-\varphi+\varphi \tau)(\Delta \eta)^{2}}+\frac{E c}{\operatorname{Re}(1-\varphi+\varphi \tau)(1-\varphi)^{2.5}}\left(\frac{W_{i+1}-W_{i-1}}{2 \Delta \eta}\right)^{2},
\end{gathered}
$$

with initial conditions

$$
W_{i}(0)=\theta_{i}(0)=0,1 \leq i \leq N+1,
$$


and boundary conditions

$$
W_{1}=0, \theta_{1}=0, W_{N+1}=1, \theta_{N+1}=\theta_{N}(1-m B i \Delta \eta) .
$$

Considering Eqs. (21)-(23), we can see that they are first order ordinary differential equations with known initial conditions. So they can be easily solved iteratively using the Runge-Kutta Fehlberg integration technique ( $\mathrm{Na}$ 1979) implemented on a computer using Matlab. From the process of numerical computation, the skin-friction coefficient and the Nusselt number in Eq. (16) are also worked out and their numerical values are presented graphically.

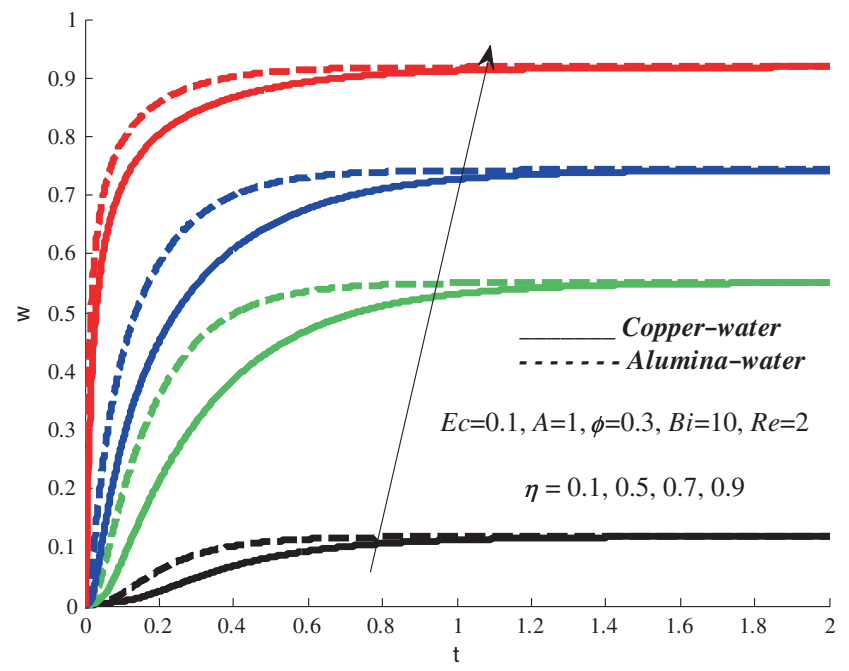

Figure 2. Nanofluids velocity profiles with increasing time.

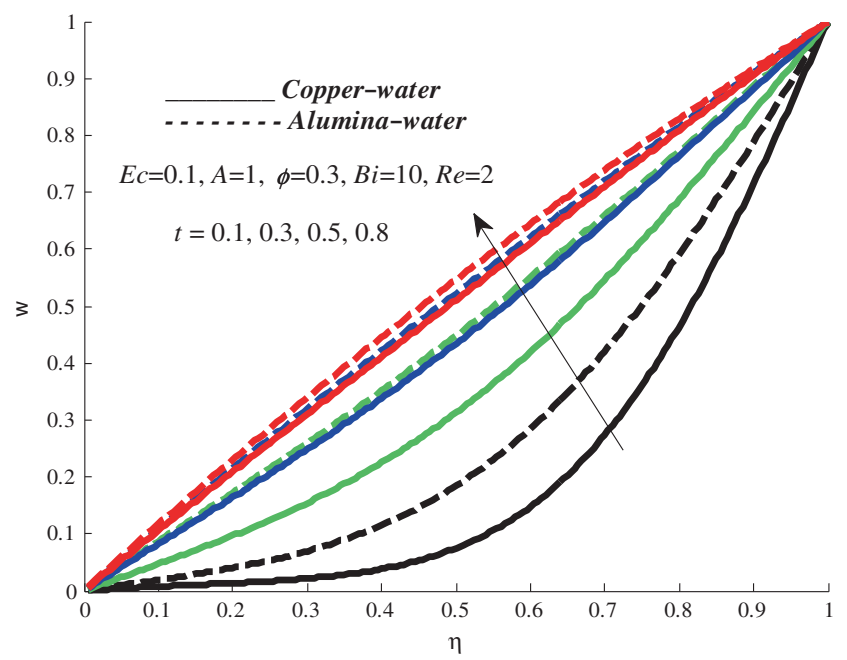

Figure 3. Nanofluids velocity profiles across the channel with increasing time. 


\section{Results and discussions}

In this paper, the pure water has been considered as the base fluid, copper $(\mathrm{Cu})$ and Alumina $\left(\mathrm{Al}_{2} \mathrm{O}_{3}\right)$ as nanoparticles. The Prandtl number of the base fluid (water) is kept constant at 6.2 and the effect of solid volume fraction is investigated in the range of $0 \leq \varphi \leq 0.3$. Numerical solution for the representative velocity field, temperature field, skin friction, Nusselt number, entropy generation rate and Bejan number has been carried out by assigning some arbitrary chosen specific values to various thermophysical parameters controlling the flow system (figures 2-27). Moreover, it is important to note that $\varphi=0$ correspond to base fluid scenario while $\varphi>0$ correspond to nanofluids scenario. The detailed discussion and graphical representation of the results of above equations are reported in this section.

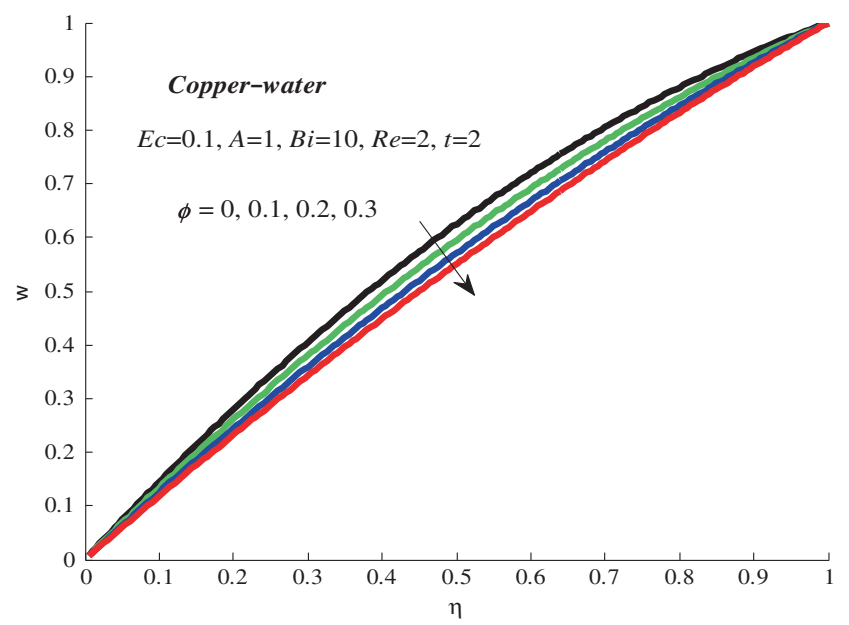

Figure 4. Nanofluid velocity profiles with increasing $\varphi$.

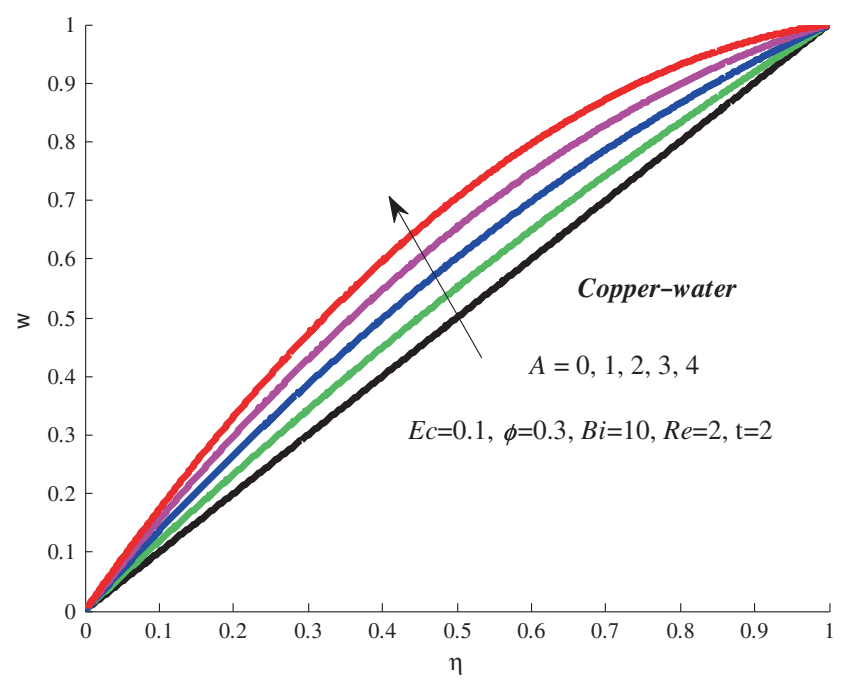

Figure 5. Nanofluid velocity profiles with increasing $A$. 


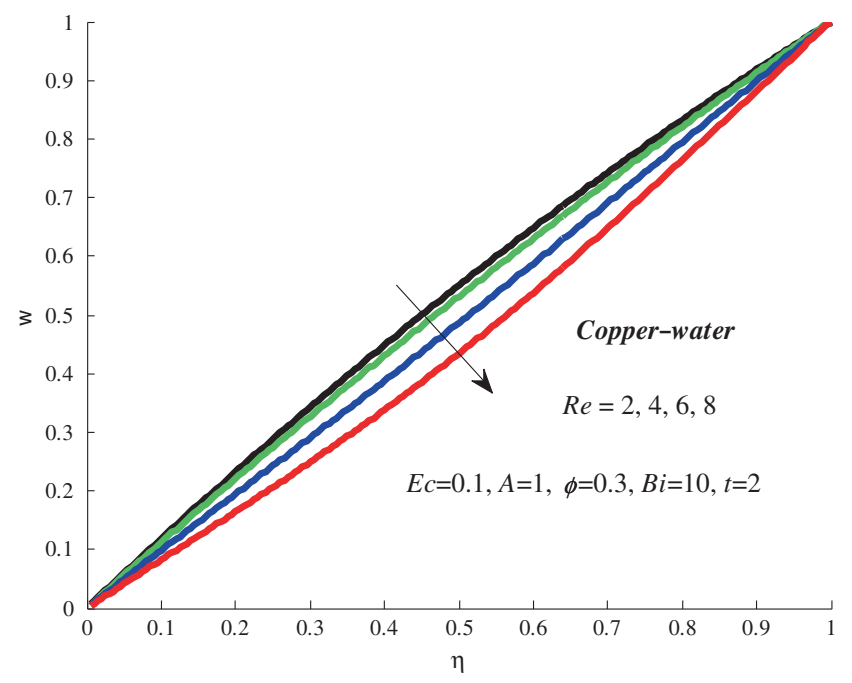

Figure 6. Nanofluid velocity profiles with increasing $R e$.

\subsection{Effects of parameter variation on velocity profiles}

Graphical results are presented in figures 2-6 to give a better understanding of the effect of different parameters on the velocity profiles. In general, the velocity increases with time for a given set of parameter values until a steady state profile is achieved as shown in figure 2 . It can be noted that the steady state velocity profile in this study is attained at $t=1.4$. Figure 3 shows an interesting observation that alumina-water nanofluid tends to flow faster than copper-water nanofluids. This result may be due to the high density of copper nanoparticle as compared to alumina nanoparticle. Figures 4-6 show the effects of parameters variation on the velocity profiles using $\mathrm{Cu}$-water nanofluid. It is observed from figure 4 that an increase in nanoparticles volume

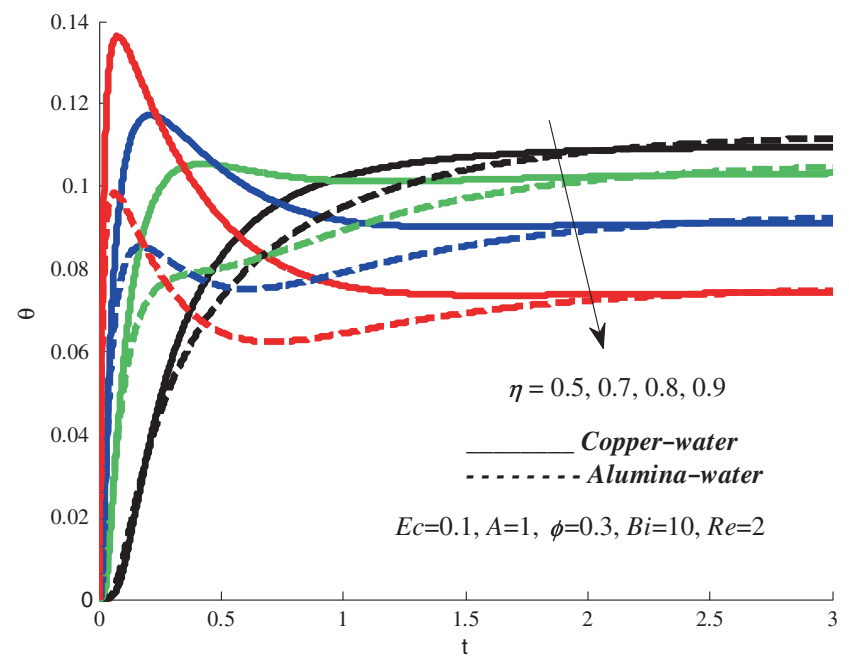

Figure 7. Nanofluids temperature profiles with increasing time. 


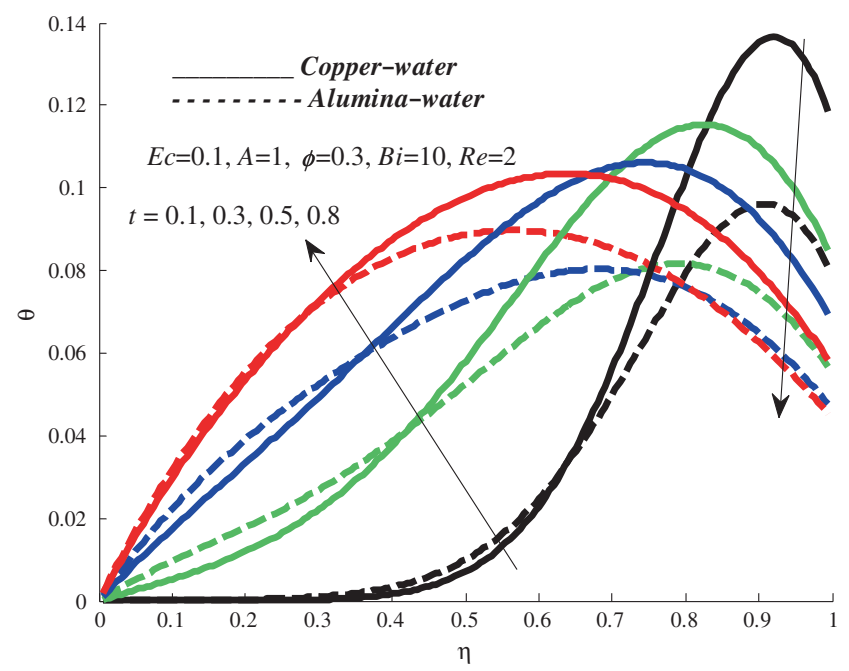

Figure 8. Nanofluids temperature profiles across the channel with increasing time.

fraction causes a decrease in the velocity profile. This result may be attributed to both the density and the dynamic viscosity of the nanofluid which increases with an increasing nanoparticles volume fraction as a result the decrease in the velocity is observed. Figure 5 shows a rise in the nanofluid velocity with an increase in the pressure gradient parameter. Automatically, it observed and true that, for standard Couette flow $(A=0)$ the velocity is small and constant compared to the generalized Couette flow scenario in which $A>0$. The opposite effect of decreasing velocity is observed when increasing Reynolds number; this happens because the viscous force increases within the flow system as indicated in figure 6.

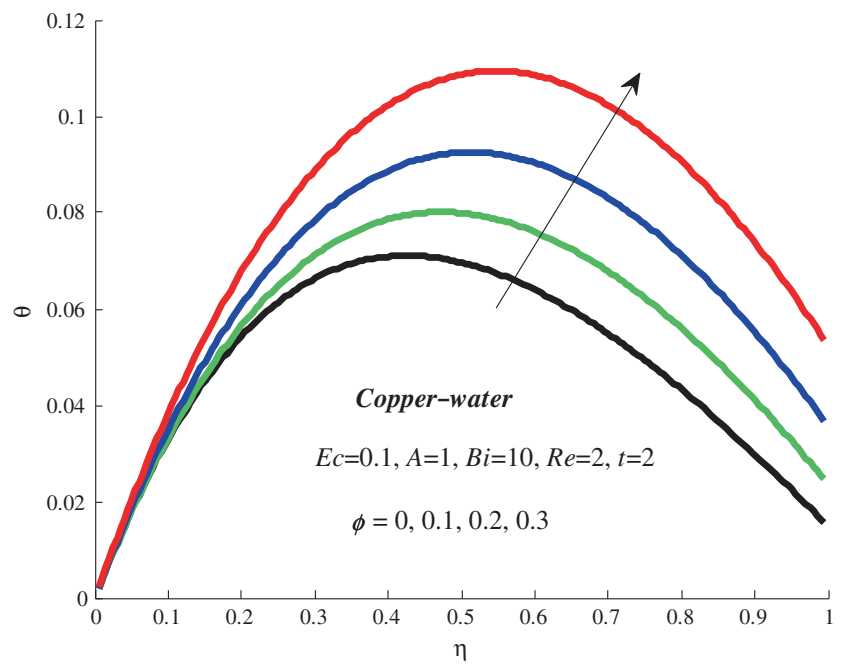

Figure 9. Nanofluid temperature profiles with increasing $\varphi$. 


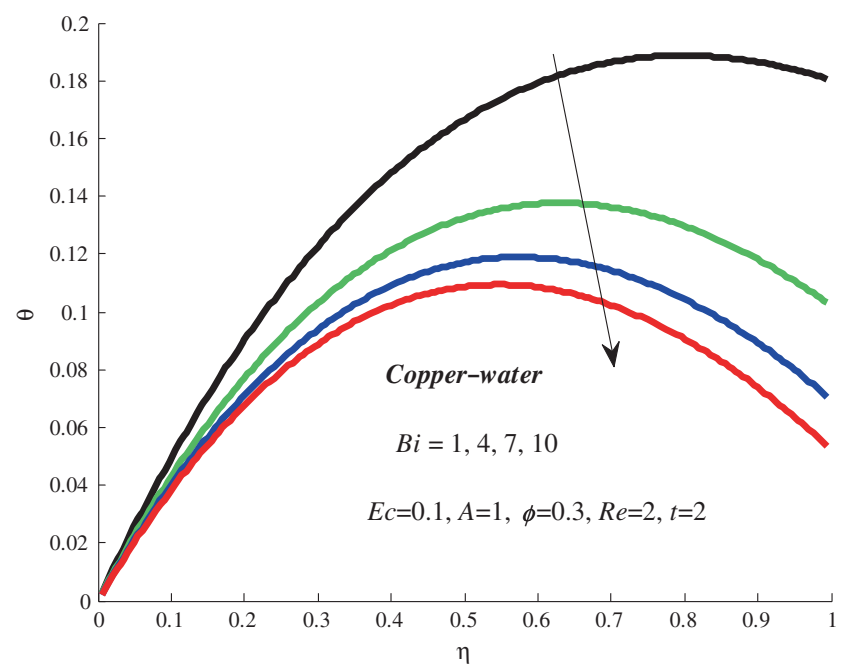

Figure 10. Nanofluid temperature profiles with increasing $B i$.

\subsection{Effects of parameter variation on temperature profiles}

Figures 7 and 8 represent the transient effects on the nanofluids temperature profiles. It is noted that the temperature decreases with time for a given set of parameter values until a corresponding steady state profile is achieved. The steady state temperature profile is attained at $t=3$. The temperature of $\mathrm{Al}_{2} \mathrm{O}_{3}$-water nanofluids, fall faster than that of $\mathrm{Cu}$-water nanofluids. In addition as the flow continues, the temperature increases near the lower wall and reverse its behaviour as it approaches the upper wall, may be is because of the moving upper plate as shown in figure 7. Comparing figure 2 and figure 7, it is observed that the steady state of velocity profile is attained earlier than that of temperature profile. It attains its maximum temperature within the channel

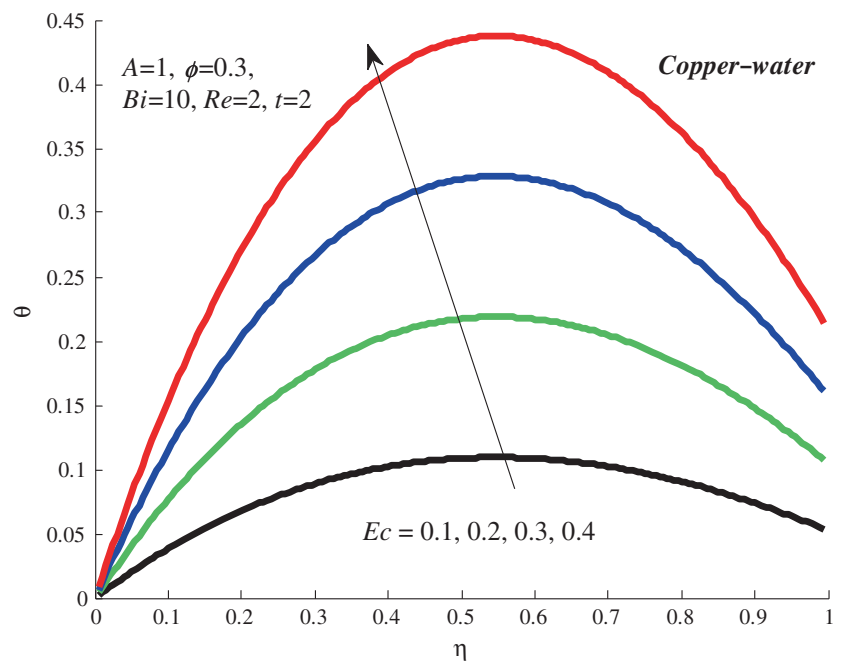

Figure 11. Nanofluid temperature profiles with increasing $E c$. 


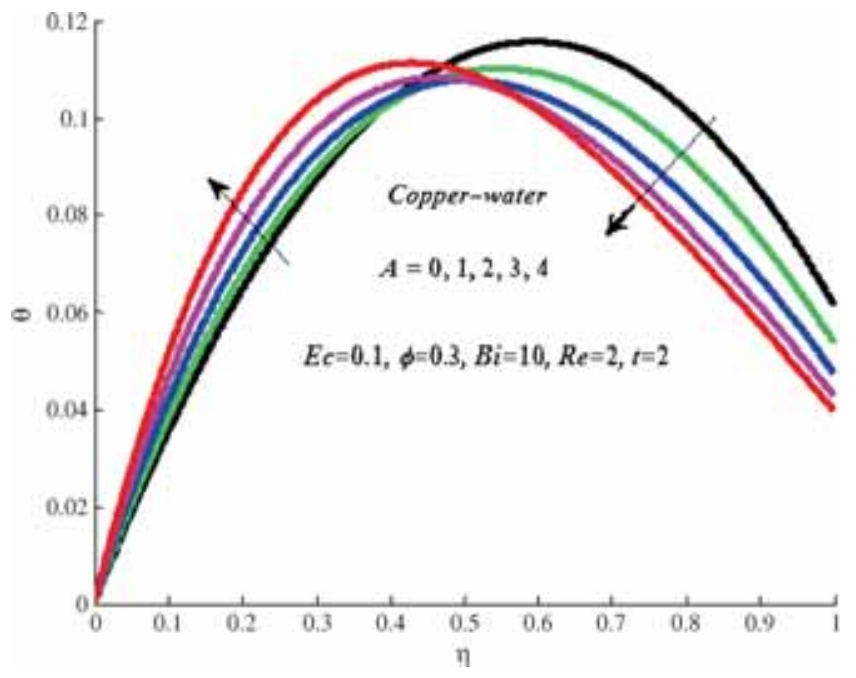

Figure 12. Nanofluid temperature profiles with increasing $A$.

and the minimum value at the walls as shown in figure 8 . The effect of parameter variation on the temperature profiles with $\mathrm{Cu}$-water nanofluid is shown in figures $9-12$. The increase in temperature profile is observed as the nanoparticles volume fraction increases as shown in figure 9. Moreover, figures 4 and 9 illustrate the flow and thermal characteristics of base fluid (water) as compare to that of nanofluids. This observation is in perfect agreement with the results of Oztop \& Abu-Nada (2008) and Makinde et al (2013), and validates the present results. The opposite trend of a decrease in temperature is noticed with a rise in Biot number, this is due to a convective cooling at the walls as shown in figure 10. It is observed in figure 11 that, temperature increases with an increase in Eckert number, this behaviour may be attributed to the viscous

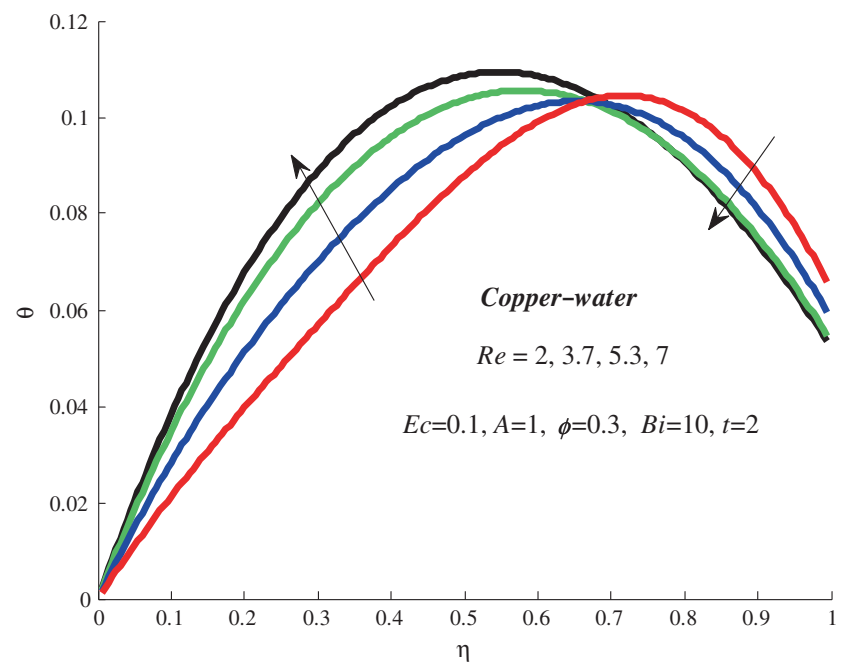

Figure 13. Nanofluid temperature profiles with increasing $R e$. 


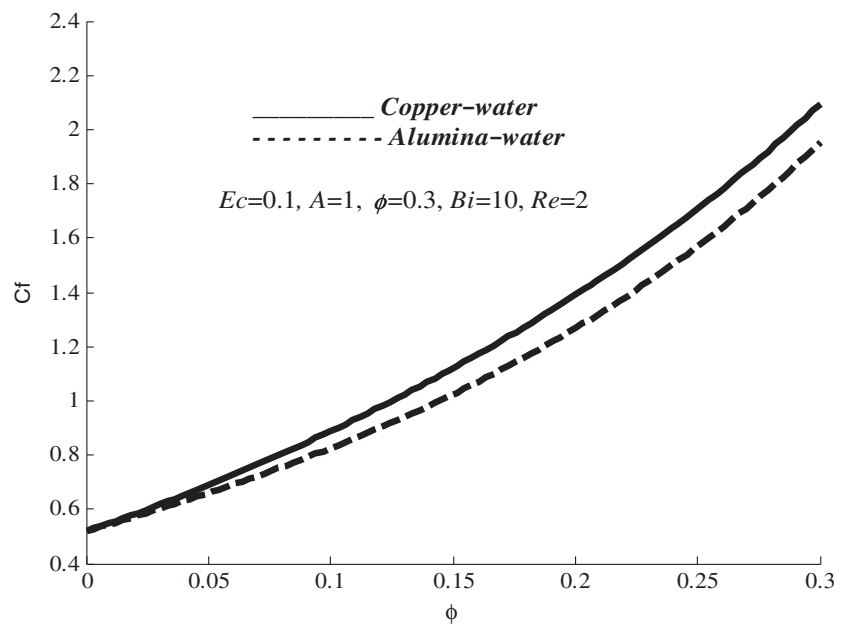

Figure 14. Skin friction with increasing $\varphi$.

dissipation. In figure 12 a rise in the nanofluid temperature and reverse situation as it approaches the upper wall is observed with an increase of the pressure gradient parameter. However, the nanofluid temperature for standard Couette flow $(A=0)$ is small at the lower wall compared to the generalizer Couette flow $(A>0)$ and vice versa at the upper wall. Figure 13, a rise in the nanofluid temperature and reverse situation as it approaches the upper wall is observed with an increase in Reynolds number. This increase and decrease in temperature can be because of the upper moving wall.

\subsection{Skin friction and Nusselt number}

The effects of parameter variation on skin friction and Nusselt number is illustrated in figures 1417. It is observed in figure 14 that the skin friction increases with an increase in nanoparticles volume fraction. This is due to an increase in the velocity gradient at the channel walls, which

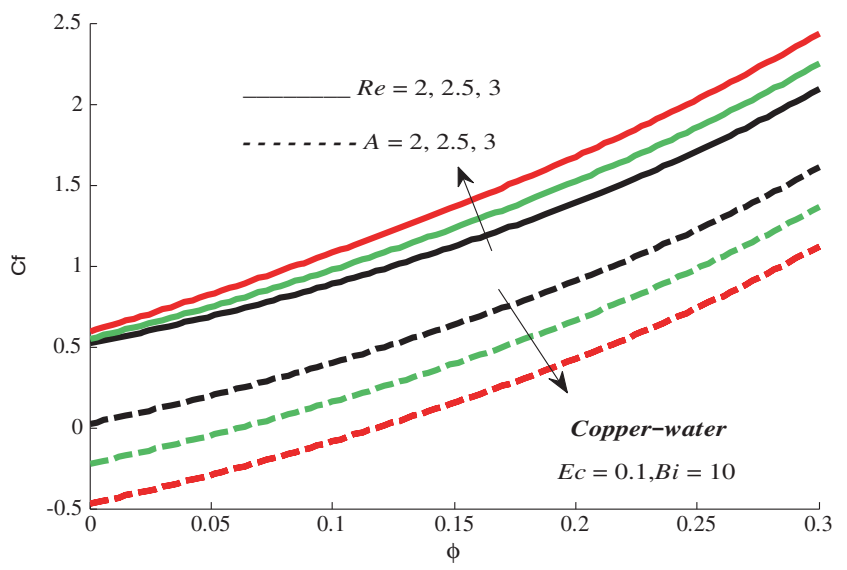

Figure 15. Skin friction with increasing $\varphi, A$ and $R e$. 


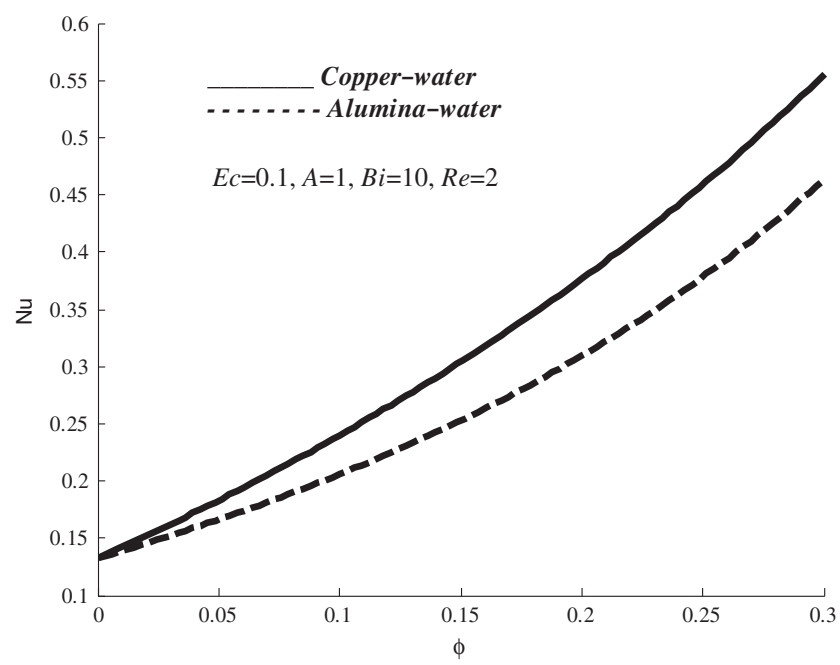

Figure 16. Nusselt number with increasing $\varphi$.

may be caused by Couette flow. Furthermore, the skin friction produced by $\mathrm{Cu}$-water nanofluid is higher than the one produced by $\mathrm{Al}_{2} \mathrm{O}_{3}$-water nanofluid. Also, the skin friction increases with an increase in the Reynolds number but decreases with increase in pressure gradient $A$ as illustrated in figure 15. The Nusselt number $\mathrm{Nu}$ is based on the thermophysical properties of nanofluids. Note that the temperature gradient depends on the thermophysical properties of nanofluids as highlighted in table 1. Figure 16 shows that the heat flux at the channel walls increases with an increase in nanoparticles volume fraction due to a rise in the temperature gradient. Moreover, the Nusselt number produced by $\mathrm{Cu}$-water nanofluid is higher than that of $\mathrm{Al}_{2} \mathrm{O}_{3}$-water nanofluid. Furthermore, the Nusselt number increases with an increase in Reynolds number and the opposite situation of decreasing Nusselt number is observed when increasing pressure

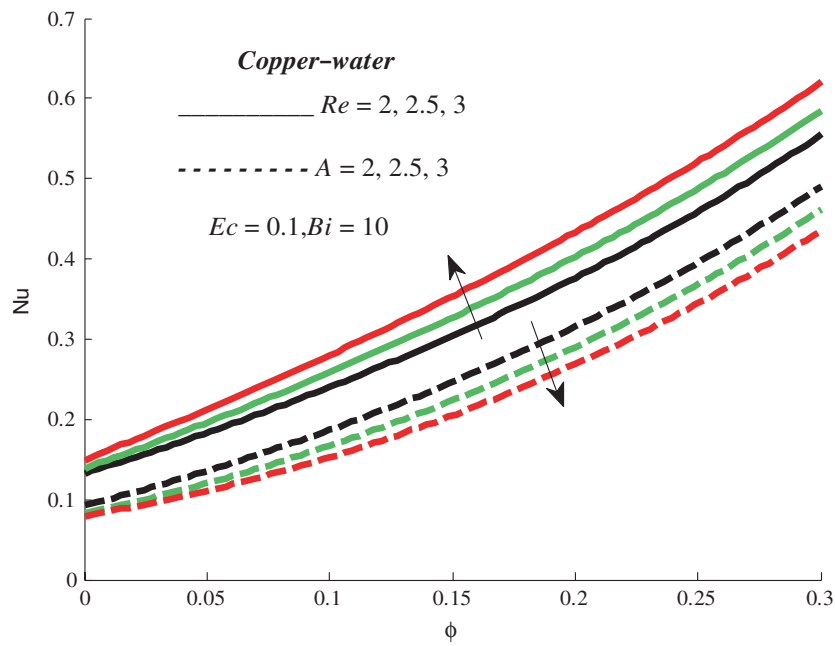

Figure 17. Nusselt number with increasing $\varphi, A$ and $R e$. 


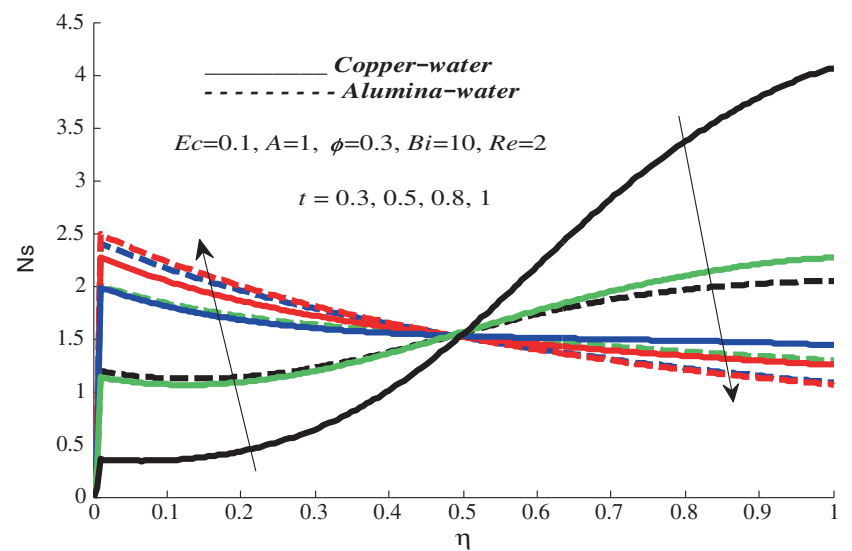

Figure 18. Entropy generation rate with increasing time.

gradient as shown in figure 17. The observed results may be attributed to movement of the upper plate (Couette flow) and viscous dissipation at the walls with a rise in parameter values. The $\mathrm{Nu}$ for the base fluid (water) can be obtained when the parameter that $\varphi=0$. Generally, the increase in $\mathrm{Nu}$ is not only due to the factor $k_{\mathrm{nf}} / k_{\mathrm{f}}$ multiplying the temperature gradient as shown in Eq. (16), but it depends on the entire thermophysical properties of nanoparticles with parameter $\varphi>0$ as shown in figures 16 and 17 .

\subsection{Effects of parameter variation on entropy generation rate}

It is noted in figure 18 that the entropy generation rate increases with time and its behaviour is reversed after half a distance for a given set of parameter values. Also, the entropy generated by $\mathrm{Al}_{2} \mathrm{O}_{3}$-water nanofluid is higher than that of $\mathrm{Cu}$-water nanofluid at the beginning but it is vice versa as it approaches the upper moving plate. This shows that the combination of moving plate

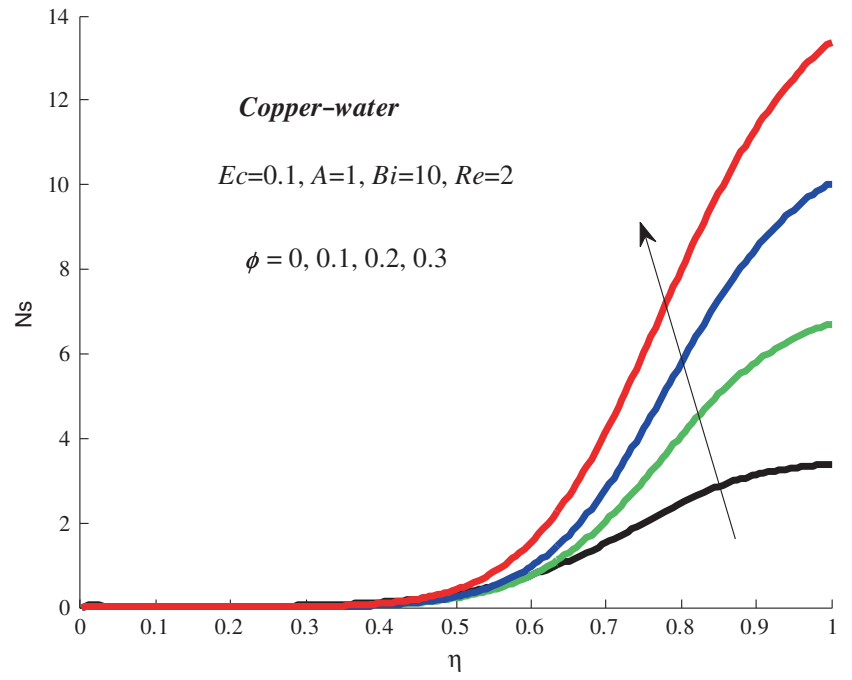

Figure 19. Entropy generation rate with increasing $\varphi$. 


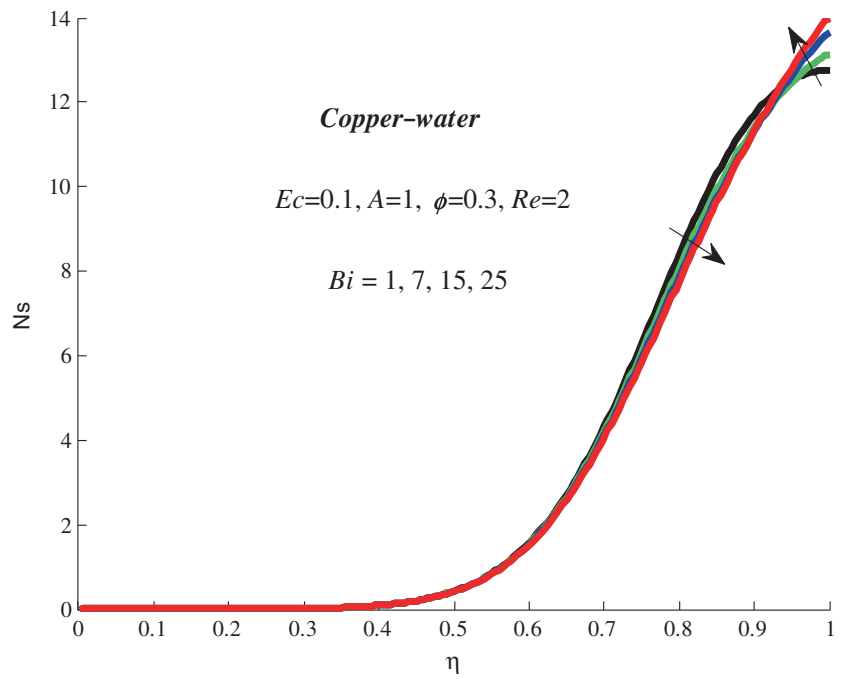

Figure 20. Entropy generation rate with increasing $B i$.

and materials with low conductivity lower entropy generation than combination of moving plate and materials with high conductivity and vice versa. So machine with the system of moving plate nanoparticle used to prepare the nanofluid should be of lower conductivity to make it more efficiency. Figure 19 shows that a rise in an entropy generation rate is observed with an increase in nanoparticles volume fraction. This is due to the fact that temperature gradients within the channel increase as $\varphi$ increases. Figure 20 shows that the entropy generation rate decreases and increases as it approaches the upper moving plate with an increase in Biot number $B i$, while it increases with an increase in Eckert number $E c$ as shown in figure 21. An entropy generation rate decreases with an increase in pressure gradient $A$ as shown in figure 22. Generally, this situation

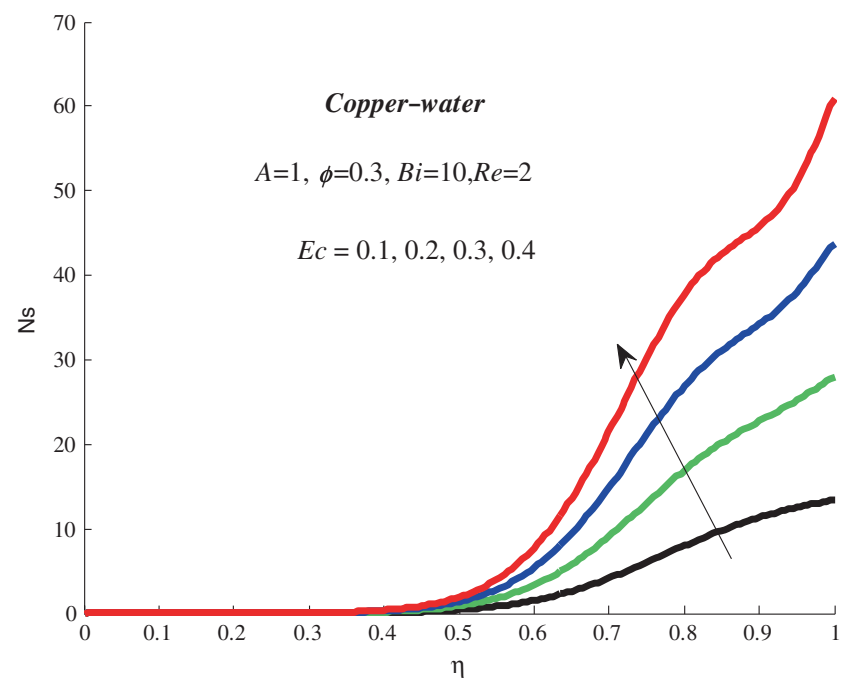

Figure 21. Entropy generation rate with increasing $E c$. 


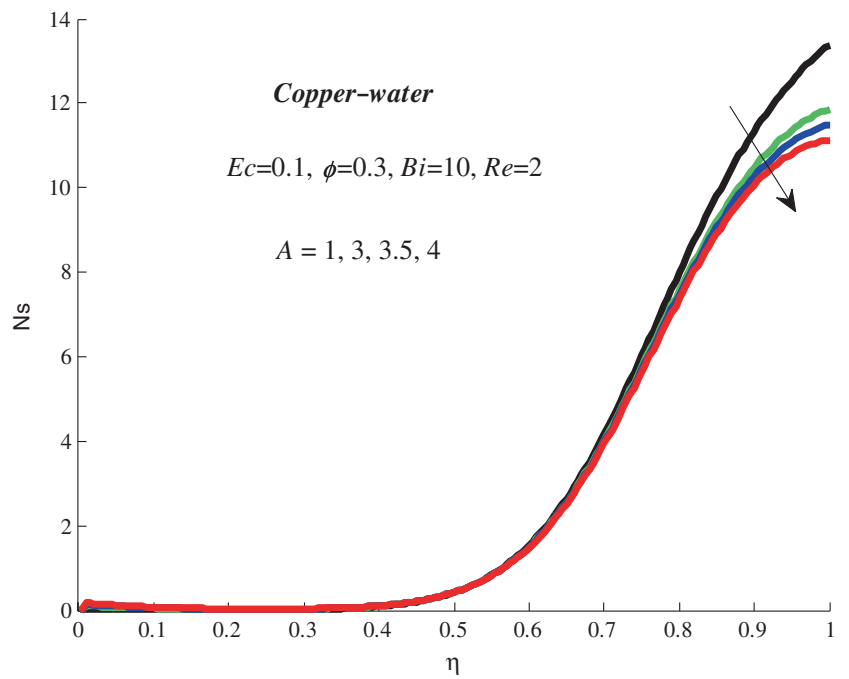

Figure 22. Entropy generation rate with increasing $A$.

may be attributed to the increase in temperature gradient with an increase in Eckert number, as well as decrease in temperature gradient with an increase in Biot number and the movement of the upper wall.

\subsection{Effects of parameter variation on Bejan number}

Figure 23 illustrates the transient effect on the Bejan number across the channel. The Bejan number increases with time near the channel walls but decreases at the channel centreline. This can be attributed to a rise in the dominant effect of fluid friction irreversibility within the channel centreline region, the heat transfer irreversibility at the channel walls and the Couette flow. The Bejan number produced by $\mathrm{Cu}$-water nanofluid near the walls is higher than that of $\mathrm{Al}_{2} \mathrm{O}_{3}$-water nanofluids. Figure 24 shows an increase in the Bejan number with an increase in nanoparticles

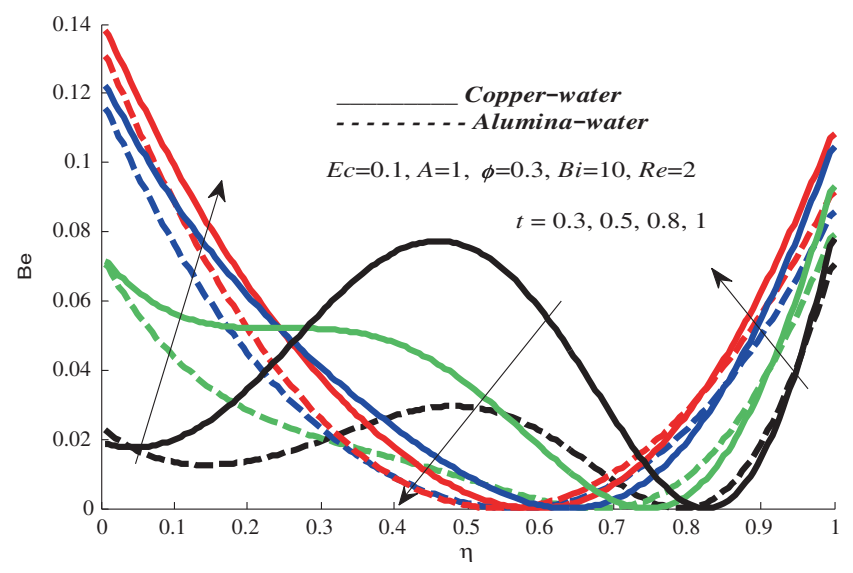

Figure 23. Bejan number with increasing time. 


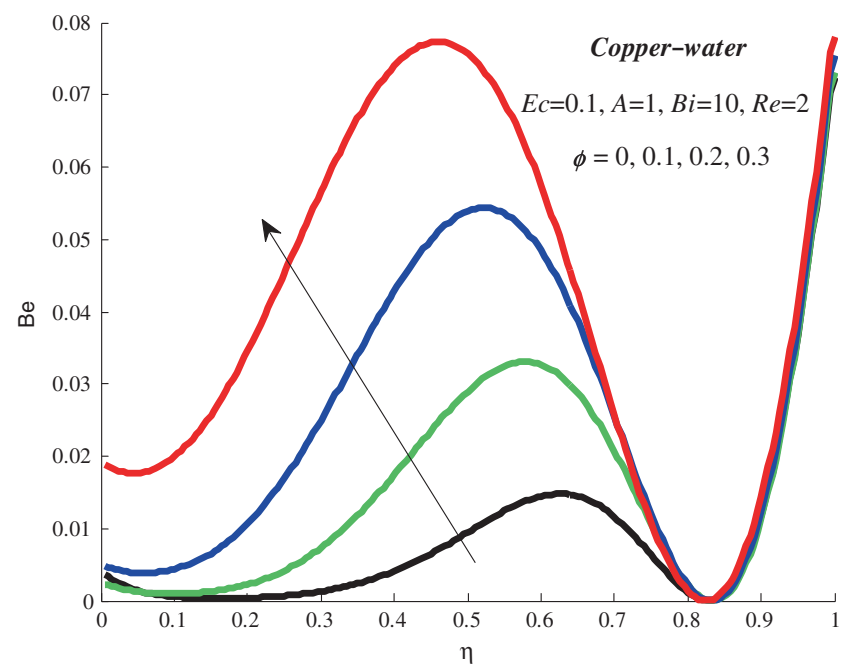

Figure 24. Bejan number with increasing $\varphi$.

volume fraction. It is also noted that the Bejan number became stable as it approached the moving wall (upper wall). This implies an increase in dominant effects of fluid friction irreversibility as $\varphi$ increases. Furthermore, as $B i$ increases, the Bejan number decreases near the lower wall and at the centre of the channel, but increases as it approaches the upper wall as shown in figure 25 . An increase in Ec causes the increase in Bejan at the lower wall, at the centre of the channel and as it approaches the upper wall of the channel as shown in figure 26. Figure 27 shows a decrease in Bejan number at the lower wall and increase at the centre of the channel and at the upper wall with an increase in pressure gradient $A$. This may be attributed to the movement of the upper wall (Couette flow) leading to a rise in the dominant effects of heat transfer irreversibility.

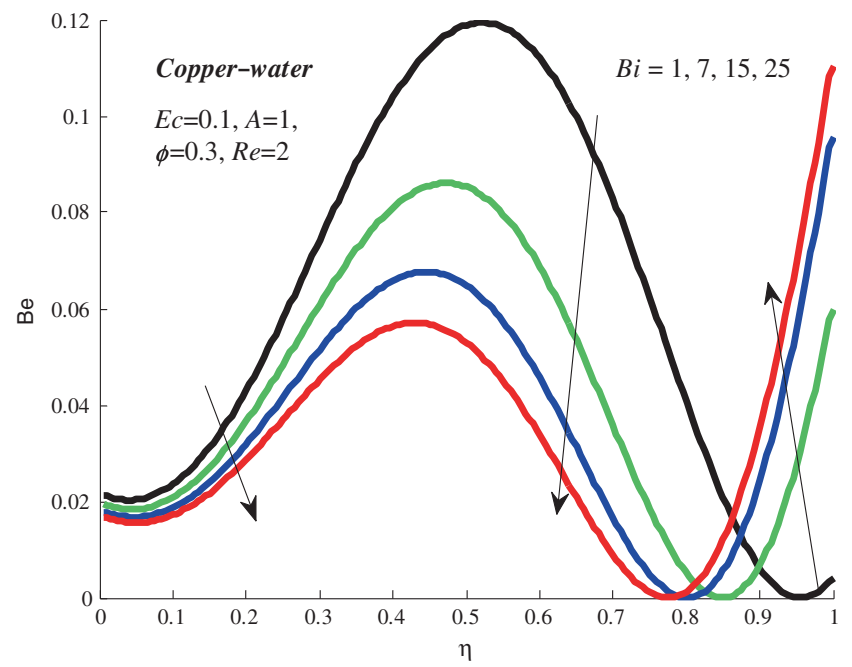

Figure 25. Bejan number with increasing $B i$. 


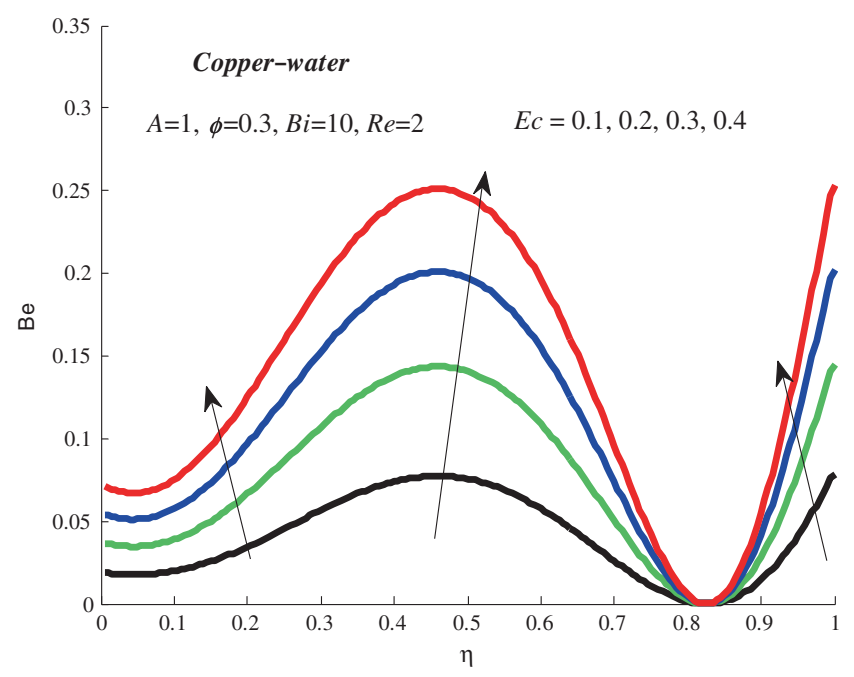

Figure 26. Bejan number with increasing $E c$.

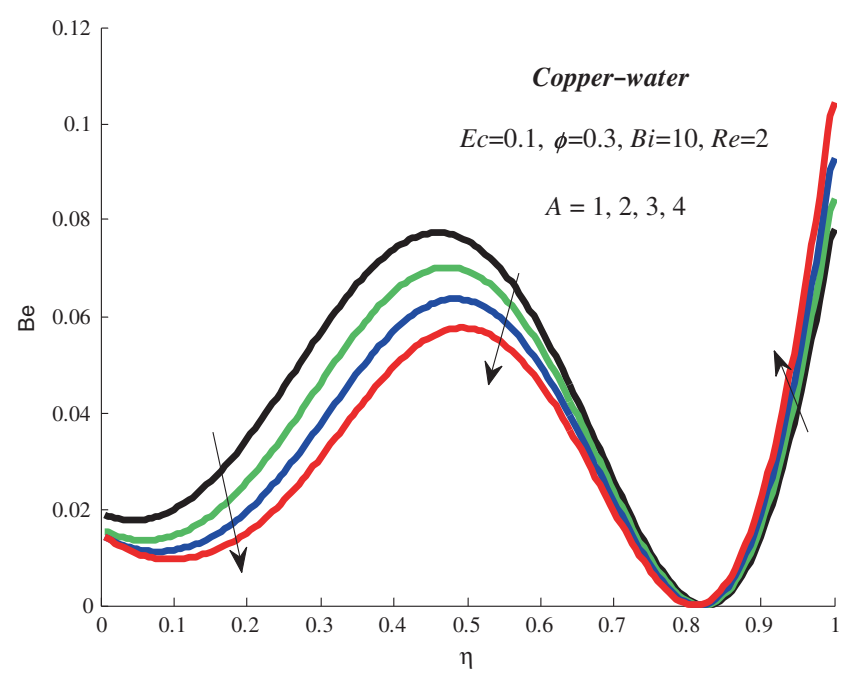

Figure 27. Bejan number with increasing $A$.

\section{Conclusions}

The flow structure, heat transfer and entropy generation in unsteady generalized Couette flow of a water-based nanofluids with convective cooling are numerically investigated. The nonlinear governing partial differential equations are solved numerically using a semi-discretization finite difference method together with the Runge-Kutta Fehlberg integration scheme. The observed results in this paper can be summarized as follows:

- The $\mathrm{Al}_{2} \mathrm{O}_{3}$-water nanofluid tends to flow faster than $\mathrm{Cu}$-water nanofluid and the velocity profile increases with $A$ but decreases with $\varphi$ and $R e$. 
- The temperature of $\mathrm{Cu}$-water nanofluid rises higher than $\mathrm{Al}_{2} \mathrm{O}_{3}$-water nanofluid and the temperature profile increases with $\varphi$ and $E c$ but decreases with $B i$. Moreover temperature profile increases near the lower wall and decreases as it approaches the upper wall with an increase in $A$, the same is observed with an increase in $R e$.

- $\mathrm{Cu}$-water nanofluid produces higher skin friction than $\mathrm{Al}_{2} \mathrm{O}_{3}$-water nanofluid and the skin friction increases with $\operatorname{Re}$ and $\varphi$ but decreases with $A$.

- $\mathrm{Cu}$-water nanofluid produces higher Nusselt number than $\mathrm{Al}_{2} \mathrm{O}_{3}$-water nanofluid and the Nusselt number increases with $\operatorname{Re}$ and $\varphi$ but decreases with $A$.

- The $\mathrm{Al}_{2} \mathrm{O}_{3}$-water nanofluid produces higher entropy generation rate than $\mathrm{Cu}-$ water nanofluid near the lower wall, but as it approaches the upper wall, $\mathrm{Cu}$-water nanofluid produces higher entropy generation rate than $\mathrm{Al}_{2} \mathrm{O}_{3}$-water nanofluid. The entropy generation increases with $\varphi$ and $E c$, it decreases with $A$. With an increase in $B i$ the entropy generation rate decreases and reverse its behaviour near the upper wall.

- The Bejan number produced by $\mathrm{Cu}$-water nanofluid is greater than $\mathrm{Al}_{2} \mathrm{O}_{3}$-water nanofluid. The Bejan number increases with time at the walls but decreases at the centre of the channel. It increases with an increase in $\varphi$. But as $B i$ increases, Bejan number decreases near the lower wall and at the centre of the channel, and increases as it approaches the upper wall. An increase in $E c$ causes the increase in the Bejan number. It is low at the lower wall, high at the centre of the channel and at the upper wall as $A$ increases.

\section{Nomenclature}

$\begin{array}{llll}u & \text { Velocity in the } x \text {-direction } & q_{w} & \text { Heat flux at the wall } \\ T & \text { Temperature of the nanofluid } & N u & \text { Nusselt number } \\ P & \text { Nanofluid pressure } & \text { Greek symbols } & \\ \bar{t} & \text { Time } & \mu & \text { Dynamic viscosity }\left(\mathrm{Nsm}^{-2}\right) \\ a & \text { Channel width }(\mathrm{m}) & \rho & \text { Density } \\ T_{w} & \text { Ambient temperature } & \alpha & \text { Thermal diffusivity }\left(\mathrm{m}^{2} \mathrm{~s}^{-1}\right) \\ C_{p} & \text { Specific heat at constant pressure } & \varphi & \text { Nanoparticle volume fraction } \\ & \left(\mathrm{kJkg}^{-1} \mathrm{~K}^{-1}\right) & & \\ B e & \text { Bejan number } & \tau_{w} & \text { Wall shear stress } \\ B i & \text { Biot number } & \text { Subscripts } & \\ K & \text { Thermal conductivity }\left(\mathrm{Wm}^{-1} \mathrm{~K}^{-1}\right) & n f & \text { Nanofluid } \\ \mathrm{Pr} & \text { Prandtl number } & w & \text { Wall } \\ E c & \text { Eckert number } & f & \text { Fluid } \\ R e & \text { Reynolds number } & s & \text { Solid }\end{array}$

\section{References}

Abu-Nada E 2008 Application of nanofluids for heat transfer enhancement of separated flows encountered in a backward facing step. Int. J. Heat Fluid Flow 29: 242-249

Bejan A 1982 Second-law analysis in heat transfer and thermal design. Adv. Heat Transfer 15: 1-58

Bejan A 1996 Entropy generation minimization. CRC: Boca Raton, NY

Buongiorno J 2006 Convective transport in nanofluids. J. Heat Transfer 128: 240-250

Choi S U S 1995 Enhancing thermal conductivity of fluids with nanoparticles. In: Proceedings of ASME International Mechanical Engineering Congress and Exposition, San Franciscos, USA, ASME, FED 231/MD 66, 99-105 
Choi S U S, Zhang Z G, Yu W, Lockwood F E and Grulke E A 2001 Anomalously thermal conductivity enhancement in nanotube suspensions. Appl. Phys. Lett. 79: 2252-2254

Makinde O D 2012 Analysis of Sakiadis flow of nanofluids with viscous dissipation and Newtonian heating. Appl. Math. Mech., English ed., 33(12): 1545-1554

Makinde O D 2013a Effects of viscous dissipation and Newtonian heating on boundary layer flow of nanofluids over a flat plate. Int. J. Numer. Methods Heat Fluid flow 23(8): 1291-1303

Makinde O D 2013b Computational modelling of nanofluids flow over a convectively heated unsteady stretching sheet. Current Nanosci. 9: 673-678

Makinde O D and Aziz A 2010 Second law analysis for a variable viscosity plane Poiseuille flow with asymmetric convective cooling. Comp. Math. Appl. 60: 3012-3019

Makinde O D and Aziz A 2011 Boundary layer flow of a nanofluid past a stretching sheet with a convective boundary condition. Int. J. Thermal Sci. 50: 1326-1332

Makinde O D and Beg O A 2010 On inherent irreversibility in a reactive hydromagnetic channel flow. $J$. Thermal Sci. 19(1): 72-79

Makinde O D and Eegunjobi A S 2013 Analysis of inherent irreversibility in a variable viscosity MHD generalized Couette flow with permeable walls. J. Thermal Sci. Technol. 8(1): 240-254

Makinde O D and Theuri D 2014 Thermodynamic analysis of variable viscosity MHD unsteady generalized Couette flow with permeable walls. Appl. Comput. Math. 3(1): 1-8

Makinde O D, Khan W A and Aziz A 2013 On inherent irreversibility in Sakiadis flow of Nanofluids. Int. J. Exergy 13(2): 159-174

Motsumi T G and Makinde O D 2012 Effects of thermal radiation and viscous dissipation on boundary layer flow of nanofluids over a permeable moving flat plate. Phys. Scr. 86: 045003(8pp)

Mutuku-Njane W N and Makinde O D 2013 Combined effect of buoyancy force and Navier Slip on MHD Flow of a nanofluid over a convectively heated vertical porous plate. The Scientific World J. vol. 2013 (Article ID 725643): 8 pages

Mutuku-Njane W N and Makinde O D 2014 MHD nanofluid flow over a permeable vertical plate with convective heating. J. Comput. Theor. Nanosci. 11(3): 667-675

Na T Y 1979 Computational methods in engineering boundary value problems. New York: Academic press

Narusawa U 1998 The second-law analysis of mixed convection in rectangular ducts. Heat Mass Transfer 37: 197-203

Olanrewaju M and Makinde O D 2013 On boundary layer stagnation point flow of a nanofluid over a permeable flat surface with Newtonian heating. Chem. Eng. Commun. 200(6): 836-852

Oztop HF and Abu-Nada E 2008 Numerical study of natural convection in partially heated rectangular enclosures filled with nanofluids. Int. J. Heat Fluid Flow 29: 1326-1336

Sahin A Z 1998 Second law analysis of laminar viscous flow through a duct subjected to constant wall temperature. J. Heat Transfer 120: 76-83

Tiwari R K and Das M K 2007 Heat transfer augmentation in a two-sided lid-driven differentially heated square cavity utilizing nanofluids. Int. J. Heat Mass Transfer 50: 2002-201

Wang X Q and Mujumdar A S 2007 Heat transfer characteristics of nanofluids: A review. Int. J. Thermal Sci. 46: 1-19

Woods L C 1975 Thermodynamics of fluid systems. Oxford University Press, Oxford 